\title{
Entre o debate público e o silêncio: análise da cobertura jornalística online sobre a questão do suicídio de adolescentes e jovens negros no Brasil
}

\author{
Between public debate and silence: analysis of online journalist coverage \\ about the suicide of black teenagers and youth in Brazil
}

\section{Entre debate público y silencio: análisis de la cobertura periodística online sobre el tema del suicidio de adolescentes y jóvenes en Brasil}

\author{
Ana Carolina Pontalti Monari ${ }^{1, a}$ \\ capmonari@gmail.com | http://orcid.org/0000-0002-7474-7903 \\ Claudio Bertolli Filho ${ }^{2, b}$ \\ claudio.bertolli@unesp.br | http://orcid.org/0000-0003-3584-9736 \\ ${ }^{1}$ Universidade Estadual Paulista Júlio de Mesquita Filho. Bauru, SP, Brasil. \\ Mestrado em Comunicação pela Universidade Estadual Paulista Júlio de Mesquita Filho. \\ b Doutorado em História Social pela Universidade de São Paulo.
}

\section{Resumo}

Este artigo objetiva analisar o fomento do debate público promovido pela cobertura jornalística on-line sobre a questão do suicídio de adolescentes e jovens negros no Brasil. Para isso, foram selecionadas três reportagens de três veículos de comunicação: G1 - Ciência e Saúde (ligado às Organizações Globo), Nexo (jornal digital independente) e o Alma Preta (agência de jornalismo especializada na temática étnica do Brasil). Com o uso de teorias sobre prática jornalística, opinião pública e silêncio, além do emprego da hermenêutica de profundidade, este estudo concluiu que a mídia não promove integralmente o debate público sobre a questão. O G1 - Ciência e Saúde reproduziu o discurso da mídia hegemônica, não dando voz para os negros; o Nexo foi o jornal que tratou o tema de forma mais completa, com uso de dados e fontes, sendo negra uma delas; e o Alma Preta foi o que menos abriu espaço para identificação do público negro, com a ausência de fontes e falta de representação.

Palavras-chave: Mídia; Suicídio; Negros; Opinião pública; Teoria do silêncio.

\begin{abstract}
This article aims to analyze the public debate at online journalistic coverage on the issue of suicide among black teenagers and young people in Brazil. For this, three news from three media were selected: G1 Ciência e Saúde (linked to Globo Organizations), Nexo (independent digital newspaper) and Alma Preta (journalism agency specializing in ethnic issues in Brazil). Using theories of journalistic practice, public opinion and silence, as well as the use of deep hermeneutics, this study concluded that the media does not
\end{abstract}


fully promote public debate on the issue. G1 - Ciência e Saúde reproduced the hegemonic media discourse, giving no voice to blacks; Nexo was the newspaper that dealt with the theme most completely, using data and sources, one of them being black; and Alma Preta was the least open to the identification of the black public, with the absence of sources and lack of representation.

Keywords: Media; Suicide; Blacks; Public opinion; Silence theory.

\section{Resumen}

Este artículo tiene como objetivo analizar el debate público a través de la cobertura periodística online sobre el tema del suicidio entre adolescentes y jóvenes negros en Brasil. Para esto se seleccionaron tres medios: G1 - Ciência e Saúde (vinculado a Organizaciones Globo), Nexo (periódico digital independiente) y Alma Preta (agencia de periodismo especializada em temas étnicos en Brasil). Utilizando teorías de práctica periodística, opinión pública y silencio, así como el uso de una hermenéutica profunda, este estudio concluyó que los medios no promueven completamente el debate público sobre el tema. G1 - Ciência e Saúde reprodujo el discurso de los medios hegemónicos, sin dar voz a los negros; Nexo fue el periódico que trató el tema más completamente, utilizando datos y fuentes; y Alma Preta fue la menos abierta a la identificación del público negro, con la ausencia de fuentes y la falta de representación.

Palabras clave: Medios de comunicación; Suicidio; Negros; Opinión pública; Teoría del silencio.

Contribuição dos autores:

Concepção e desenho do estudo Ana Carolina Pontalti Monari e Claudio Bertolli Filho.

Aquisição, análise ou interpretação dos dados: Ana Carolina Pontalti Monari e Claudio Bertolli Filho.

Redação do manuscrito: Ana Carolina Pontalti Monari e Claudio Bertolli Filho.

Revisão crítica do conteúdo intelectual: Ana Carolina Pontalti Monari e Claudio Bertolli Filho.

Declaração de conflito de interesses: não há.

Fontes de financiamento: não houve.

Considerações éticas: não há.

Agradecimentos/Contribuições adicionais: não há.

Histórico do artigo: submetido: 7 ago. 2018 | aceito: 11 nov. 2019 | publicado: 20 dez. 2019.

Apresentação anterior: não houve.

Licença CC BY-NC atribuição não comercial. Com essa licença é permitido acessar, baixar (download), copiar, imprimir, compartilhar, reutilizar e distribuir os artigos, desde que para uso não comercial e com a citação da fonte, conferindo os devidos créditos de autoria e menção à Reciis. Nesses casos, nenhuma permissão é necessária por parte dos autores ou dos editores. 


\section{Introdução}

O Ministério da Saúde do Brasil lançou em maio de 2019 a cartilha Óbitos por Suicídio entre Adolescentes e Jovens Negros ${ }^{1}$. O documento traz o panorama desta situação no país e também oferece dados para que a sociedade discuta a questão - em média, 800 mil pessoas morrem por suicídio todos os anos no mundo, de acordo com a Organização Mundial da Saúde (OMS) ${ }^{1}$ - além de apontar as possíveis causas que fazem com que indivíduos tirem suas próprias vidas. Segundo o estudo, esta é a principal causa de morte entre os jovens de 15 a 29 anos, sendo a quarta entre negros dessa mesma faixa etária.

Este grave problema de saúde pública, segundo a cartilha ${ }^{1}$, é um fenômeno social presente ao longo da história da humanidade e é associado a uma série de fatores psicológicos, culturais, morais, socioambientais, econômicos, entre outros. Quando o assunto se volta para a morte autoprovocada de negros, a questão vai além, pois o preconceito, a discriminação racial e o racismo institucional também se transformam em fatores de risco para essa população.

A Política Nacional de Saúde Integral da População Negra ${ }^{1}$ afirma que, muitas vezes, queixas raciais podem ser subestimadas ou individualizadas e ainda podem responsabilizar aqueles que sofrem o preconceito. O estigma que cerca a temática, aliado a elementos estruturantes como o racismo, contribui para o silenciamento ao redor da questão, além das dificuldades de se falar abertamente sobre o assunto, seja na mídia ou em sociedade.

A veiculação de casos de suicídio costuma ser feita com cautela pela mídia. A OMS, por exemplo, disponibiliza de forma on-line e gratuita a obra Prevenção do Suicídio: Um Manual para Profissionais da Mídia², em que fornece diretrizes sobre como jornalistas e demais profissionais da área podem lidar e transmitir esse conteúdo para seu público. De acordo com o órgão de saúde pública, a disseminação apropriada de informação e o aumento da conscientização sobre o tema constituem-se elementos essenciais para o sucesso de programas de prevenção do suicídio.

Sabe-se que a "mídia desempenha um papel significativo na sociedade atual, ao proporcionar uma ampla gama de informações, através dos mais variados recursos. Influencia fortemente as atitudes, crenças e comportamentos da comunidade e ocupa um lugar central nas práticas políticas, econômicas e sociais. Devido a esta grande influência, os meios de comunicação podem ter um papel ativo na prevenção do suicídio"2.

Os meios de comunicação podem contribuir para trazer o debate sobre o assunto à tona na sociedade brasileira. Moreira e Paulino ${ }^{3}$ dizem que a mídia, entretanto, pouco aborda a questão e, quando a faz, é quase sempre sob uma enxurrada de eufemismos. Os pesquisadores ainda consideram que o assunto só é noticiado pelos veículos de comunicação quando o fato tem aspectos fora do 'comum', ou seja, quando ocorre em circunstâncias diferenciadas ou quando acomete personagens em destaque pela sociedade. "Duas exceções ao silêncio sobre o tema estão em documentos produzidos pelo Serviço Público de Radiodifusão. Herdeiro de debate iniciado pela Radiobrás, o Manual de Jornalismo da EBC estabelece que o suicídio só deve ser noticiado quando a relevância do fato transcenda o âmbito privado e a divulgação depende de autorização prévia da Diretoria de Jornalismo. Outras abordagens são aceitas, quando abordam o tema sob a perspectiva de saúde pública abordando fatores casuais e as políticas preventivas”3.

Compreende-se que a mídia é uma das responsáveis por fomentar a opinião pública. O debate, muitas vezes, é pautado pelos conteúdos que são produzidos e transmitidos pelos veículos de comunicação, sejam impressos, televisivos, radiofônicos ou on-line.

Schudson 4 define jornalismo como informação e comentário sobre assuntos contemporâneos tomados para serem publicamente importantes. Segundo ele, a mídia não apenas organiza a informação que será apresentada ao público, mas também reestrutura a audiência. $\mathrm{O}$ autor afirma que as notícias não são um espelho da realidade, pois são uma representação do mundo e todas as representações são seletivas. Ainda de acordo com ele, o retrato do mundo apresentado pela mídia para as audiências leva em consideração as preferências e percepções livres dos controles democráticos de editores, redatores e repórteres ${ }^{4}$. 
Os cidadãos, portanto, se utilizam dessas informações propagadas pelos meios de comunicação - que são previamente selecionadas pelos jornalistas e editores - para tecer suas próprias opiniões sobre os fatos que lhe são apresentados. É o que Lippmann ${ }^{5}$ expõe como opinião pública, quando ele diz que são "aquelas imagens que são feitas por grupos de pessoas, ou por indivíduos agindo em nome dos grupos (...)”. Não verbalizar sobre um acontecimento, por exemplo, pode ser uma maneira dos meios de difusão de informação atuarem na formação da opinião pública na sociedade.

Sendo assim, o silêncio é um ponto a ser destacado quando o assunto é a cobertura jornalística de temas sobre suicídio na mídia, principalmente quando envolve a população negra. Durante a Idade Média, a morte autoprovocada era distinguida entre as classes mais favorecidas e as menos favorecidas. Oliveira e Barros ${ }^{6}$ afirmam que a ação cometida pelas pessoas mais pobres era fortemente rejeitada pela igreja, enquanto que se um nobre tirasse sua própria vida, seja qual fosse a causa, este era considerado corajoso, honrado e respeitável. O modo de veiculação do suicídio na sociedade provém desse período e fez com que se criasse a cultura de não falar sobre o assunto, como uma forma de reprimir a ação.

Quando o assunto é autocídio de afro-brasileiros, o estigma em torno desse problema de saúde pública, aliado a elementos estruturantes, tais como o racismo, aumenta o silenciamento em torno da questão, além de contribuir para uma dificuldade de se discutir abertamente a temática ${ }^{1}$. O documento do Ministério da Saúde ${ }^{1}$ informa que a Política Nacional de Saúde Integral da População Negra reconhece o racismo, as desigualdades étnico-raciais e o racismo institucional como determinantes sociais das condições de saúde e também reforça que os jovens, sobretudo os jovens negros, são um dos grupos mais afetados pela morte autoprovocada.

Orlandi ${ }^{7}$ é uma das pesquisadoras da atualidade que trabalha com o estudo do silêncio. Para ela, o silêncio é visto como fator essencial, como a própria condição do significar, em que há a existência de um modo de estar em silêncio e de um modo de estar no sentido. Em sua obra As formas do silêncio: no movimento dos sentidos (1997), ela propõe livrar o silêncio do sentido 'passivo' e 'negativo' que lhe foi atribuído pelas formas sociais da cultura contemporânea e também ligá-lo ao não dizer da história e da ideologia.

Segundo Orlandi , o silêncio é a capacidade do sujeito trabalhar sua condição constitutiva, sua relação com o outro, ou seja, ele se situa na relação do um com o múltiplo. Diante disso, é impossível dizer que ausência de som, de palavras e de gestos, entre outros, caracteriza-se apenas pelo vazio, uma vez que essa 'recusa em falar' pode, muitas vezes, significar inúmeras compreensões. Ela ainda esclarece que, sob esta perspectiva, seria possível entendê-lo como o não dito que é história, à medida que demonstra a relação do sentido com o imaginário, com a língua e com a ideologia.

No silêncio sobre questões do suicídio, a mídia acaba por dar 'margem' para outro tipo de veiculação, que é feita de forma 'velada', uma vez que há certa curiosidade em relação ao tema por parte da população. Não é incomum, na modernidade tardia, a divulgação pelas redes sociais de fotos e vídeos de pessoas que tiraram a própria vida - principalmente com a rápida transmissão de mensagens proporcionada por aplicativos como o Facebook Messenger, Telegram e WhatsApp.

Em 2014, a Associação Brasileira de Psiquiatria, em parceria com o Conselho Federal de Medicina (CFM), publicou uma cartilha para combater o suicídio ${ }^{8}$. O objetivo do documento é diminuir o número de ocorrências no Brasil, com foco na prevenção que, de acordo com a instituição, vai muito além dos profissionais e da rede de saúde.

A associação acredita que a mídia desempenha papel fundamental nessa questão, pois, é por meio dela, que as pessoas podem obter informações para evitar o ímpeto de tirar suas próprias vidas. Entre as responsabilidades que competem aos meios de comunicação estão "campanhas preventivas e maior regulação da veiculação em casos de tentativas"8.

O objetivo, portanto, deste artigo é analisar a cobertura jornalística sobre a questão do suicídio de adolescentes e jovens negros no Brasil. Optou-se por três veículos online, uma vez que são meios de fácil 
acesso em todo o território nacional. Foram selecionadas três reportagens sobre o assunto em três diferentes portais de notícia: G1 - Ciência e Saúde (grande mídia ligada às Organizações Globo), Nexo (jornal digital de iniciativa independente) e o Alma Preta (agência de jornalismo especializada na temática racial do Brasil). O intuito é verificar a forma com que esses três sites abordaram a questão do aumento do número de suicídios entre jovens e adolescentes negros entre 2012 e 2016, a partir da divulgação da cartilha Óbitos por Suicídio Entre Adolescentes e Jovens Negros¹ lançada em maio de 2019 pelo Ministério da Saúde. A finalidade deste artigo é constatar se esses portais de notícia fomentaram o debate público sobre a temática ou se apenas perpetuaram o silêncio sobre a questão.

\section{Estratégia metodológica}

Este estudo busca verificar a cobertura sobre a questão do suicídio de jovens negros no Brasil a partir de três portais de notícias: G1 - Ciência e Saúde, Nexo e Alma Preta. Esses três sites foram selecionados por compreenderem modelos mercadológicos diferentes: o G1 - Ciência e Saúde faz parte das Organizações Globo, uma das maiores e mais importantes empresas de comunicação do país; o Nexo, por outro lado, é um jornal digital de iniciativa independente, financiado com recursos próprios e por meio das assinaturas de seus leitores, tendo como premissa a não oferta de espaços de publicidade; e, por fim, o Alma Preta é uma agência de jornalismo especializado na temática racial do Brasil.

O artigo irá analisar uma reportagem de cada um dos meios de comunicação selecionados sobre a divulgação de dados da cartilha Óbitos por Suicídio Entre Adolescentes e Jovens Negros ${ }^{1}$, lançada em maio de 2019 pelo Ministério da Saúde.

Para a investigação, optou-se pelo uso de teorias sobre prática jornalística preconizadas por Schudson ${ }^{4,9,10}$; sobre opinião pública defendida por Walter Lippmann 5 ; e sobre a teoria do silêncio, que é abordada por Orlandi ${ }^{7}$ Em relação à metodologia, optou-se pela hermenêutica de profundidade de Thompson ${ }^{11}$. Bastos e Porto explicam que esta “(...) procura mostrar o papel da interpretação como um processo, uma metodologia, que busca descobrir o originalmente escondido por uma tradição que nos foi legada por uma exegese distorcida, usando para tal de uma destruição, ou seja, de uma desconstrução hermenêutica. A desconstrução hermenêutica, assim, não critica o passado, mas o presente e sua abordagem distorcida, subvertendo as explicações tradicionais e seus conceitos dogmaticamente inquestionados, não destruindo de fato, mas procurando revelar possibilidades ainda não percebidas"12.

Thompson ${ }^{11}$ afirma que este referencial "coloca em evidência o fato de que o objeto de análise é uma construção simbólica significativa, que exige uma interpretação. Por isso, devemos conceder um papel central ao processo de interpretação, pois somente desse modo poderemos fazer justiça ao caráter distintivo do campo-objeto".

O método interpretativo da hermenêutica de profundidade consiste em três fases de análise: análise sócio histórica, análise formal ou discursiva e interpretação/reinterpretação. Na primeira fase, de acordo com Thompson ${ }^{11}$, o pesquisador irá investigar as condições sociais e histórias em que as formas simbólicas foram produzidas. Para isso, é preciso descrever as situações espaço-temporais, reconstruir ambientes ou campos de interação e suas regras, além das instituições sociais. Os meios técnicos de construção de mensagens e de transmissão também são analisados, uma vez que as formas simbólicas necessitam se adequar a esses meios que, por sua vez, fazem parte de aparatos institucionais que lhe conferem características próprias ${ }^{13}$.

Na segunda etapa, rotulada de análise formal ou discursiva, investiga-se a organização interna das formas simbólicas indicando suas características e relações estruturais. Para isso, podem-se utilizar diversos métodos, tais como análise da conversação, semiótica e análise sintática, entre outros. A última etapa, conhecida como interpretação/reinterpretação, disponibiliza um procedimento que sintetiza a análise formal ou discursiva apresentando possíveis significados e referências ${ }^{11-13}$. 
Diante disso, o pesquisador que se utiliza dessa metodologia faz um mecanismo de ida e volta no texto, com o objetivo de verificar os sentidos que estão 'escondidos', fazendo, portanto, um exercício de compreender e interpretar o conteúdo para revelar os significados que estão ocultos. O exercício interpretativo, entretanto, é aberto e pode proporcionar significados divergentes daqueles propostos pelos sujeitos analisados, sendo, portanto, uma projeção de possíveis significados.

Embora a teoria do silêncio, elaborada por Orlandi’, seja desenvolvida com base teórico-metodológica da Análise de Discurso de Linha Francesa ${ }^{14}$ - que, ao contrário da hermenêutica de profundidade, acredita que não se deve buscar os sentidos ocultos no texto, como se houvesse um significado fixo -, optou-se nesta investigação pela sua conciliação com a metodologia de Thompson ${ }^{11}$, pois esta apresenta mecanismos que auxiliam na exploração do caráter da incompletude da linguagem. Com os mecanismos interpretativos, portanto, buscou-se compreender as perspectivas propostas ou não pelos autores do texto nas lacunas deixadas por eles no conteúdo estudado, partindo do pressuposto de que todo dizer é uma relação fundamental com o não dizer ${ }^{15}$.

Em suma, a hermenêutica de profundidade proporciona, por meio da interrogação e da reinterpretação, reelaborar historicamente os sentidos e os significados da compreensão humana, estabelecendo, portanto, uma construção de uma ação comunicativa na dimensão comunicacional ${ }^{12}$. Ela também oferece ferramentas para que se possa analisar as significações presentes nas mensagens inacabadas ou incompletas presentes em um texto. Os dados das análises dos três portais de notícias foram, posteriormente, comparados para verificar diferenças e/ou semelhanças entre as coberturas jornalísticas sobre a questão do suicídio entre jovens e adolescentes negros no Brasil.

\section{Análise das reportagens sobre suicídio de adolescentes e jovens negros produzidas pelo G1 - Ciência e Saúde, Nexo e Alma Preta}

\section{G1 - Ciência e Saúde}

A reportagem do G1 - Ciência e Saúde sobre a temática foi publicada no dia 21 de maio de 2019, e o seu título é Índice de suicídio entre jovens e adolescentes negros cresce e é $45 \%$ maior do que entre os brancos ${ }^{16}$. Sua linha-fina complementa a informação ao noticiar que "Dados do Ministério da Saúde mostram que o risco

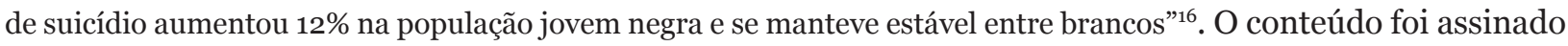
pela jornalista Patrícia Figueiredo. 


\section{Índice de suicídio entre jovens e adolescentes negros cresce e é $45 \%$ maior do que entre brancos}
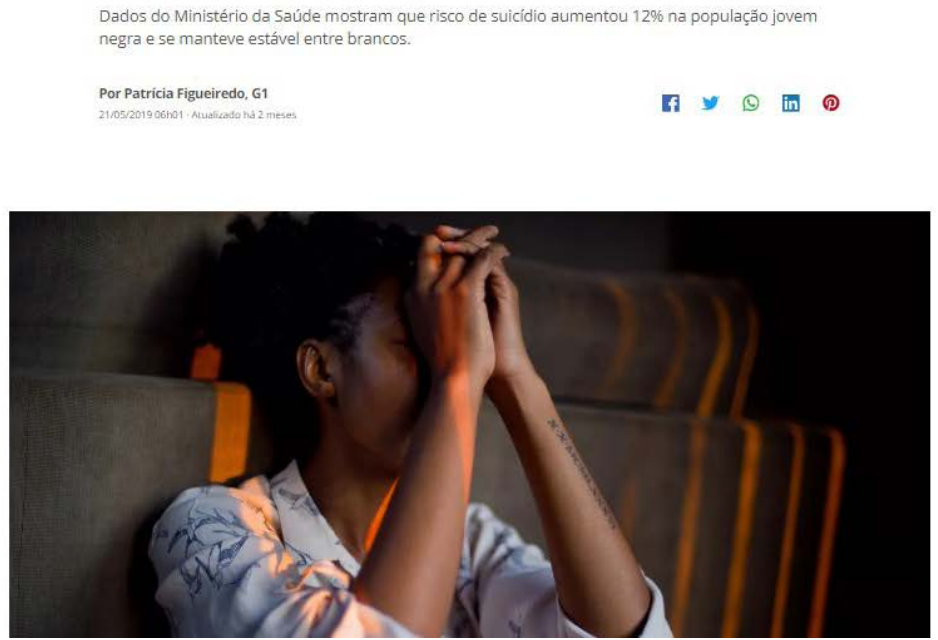

Figura 1 - Reportagem G1 - Ciência e Saúde

Fonte: G1: Ciência e Saúde (2019) ${ }^{16}$.

Os três primeiros parágrafos da notícia trazem dados da cartilha Óbitos por Suicídio Entre Adolescentes e Jovens Negros ${ }^{1}$, tais como a taxa de risco de suicídio entre jovens e adolescentes negros e a comparação desse número com o grupo de mesma faixa etária, porém formado por brancos. O quarto parágrafo, no entanto, começa a introduzir novos elementos para a reportagem, tais como a opinião da médica Rita Helena Borret, organizadora do Seminário Nacional de Saúde da População Negra na Atenção Primária, evento em que as informações do documento do Ministério da Saúde foram divulgadas.

Com o uso da fala da médica, o G1 - Ciência e Saúde inicia a discussão do tema, apontando para as principais causas do aumento de suicídio nesse grupo etário e racial. De acordo com o portal, "o maior risco de suicídio na população jovem negra está relacionado ao racismo estrutural, que causa maior sofrimento e adoecimento entre os jovens e adolescentes do que entre os brancos da mesma idade"16. O veículo de comunicação utiliza um gráfico, logo após essa informação, para ilustrar o conteúdo e transmitir a mensagem para o público-leitor de forma mais didática.

O texto ainda esclarece que os adolescentes do sexo masculino negros têm mais vulnerabilidade para a morte autoprovocada, sendo o segmento mais afetado composto por homens negros mais jovens, com idade entre 10 e 19 anos. "O risco de suicídio neste grupo foi 67\% maior do que entre adolescentes brancos do sexo masculino”"16, segundo o veículo de comunicação.

Borret foi recrutada pelo portal de notícias para explicar uma das maneiras de evitar o suicídio nesse público. Para ela, são necessárias políticas públicas focadas na saúde da população negra, pois, embora haja políticas do Sistema Único de Saúde (SUS) voltadas para atender esse grupo etário e racial, as "instituições de saúde brasileiras também são instituições racistas, tanto pelo silenciamento das situações de racismo que ocorrem dentro delas como pela reprodução do racismo estrutural que existe em nossa sociedade" ${ }^{\text {"16 }}$.

A reportagem produzida pelo G1 - Ciência e Saúde é bastante completa, com vários dados e uma fala de especialista. O site traz o assunto para o debate público, porém não dá outros elementos para que o públicoleitor possa tecer os seus próprios comentários sobre a temática. Há apenas o uso de uma especialista em saúde, o que dá margem para que o conteúdo divulgado pelo veículo de comunicação fique enviesado, com 
o parecer apenas de uma fonte. Há algumas explicações das razões desse aumento do suicídio entre jovens e adolescentes negros e há, até mesmo, uma possível solução para o problema, mas não é discutido como essas políticas públicas podem e/ou devem ser implantadas no sistema de saúde. Não há a participação, por exemplo, de organizações que trabalham com as causas e situações vivenciadas pela população negra - o que poderia trazer mais riqueza para o debate - ou de um sociólogo e/ou antropólogo para abordar a tese sobre o racismo institucional, algo que também ofereceria mais elementos para que a discussão fosse feita de forma mais plural.

Dessa forma, o G1 - Ciência e Saúde constata o que já dizia Lippmann ${ }^{5}$ sobre a imprensa no século XX. O pesquisador afirma que a ansiedade da imprensa reside mais em conquistar a atenção do público e vendêla aos seus anunciantes do que servir com informação privilegiada, de qualidade e relevante aos indivíduos, ou seja, aos cidadãos.

Orlandi ${ }^{7}$ diz que o silêncio é disperso e contínuo, e é essa continuidade que permite ao sujeito se mover nas significações e percorrer os sentidos presentes em uma narrativa. Sendo assim, é possível aferir que, ao não dar espaço para organizações que trabalham com a questão negra, o site acaba por silenciar esse público, uma vez que deixa de dar voz para a própria vítima desse tipo de ação. E ao utilizar apenas uma fonte especializada no decorrer do texto, o G1 - Ciência e Saúde faz com que o conteúdo seja oferecido à opinião pública de forma incompleta ${ }^{15}$ ou seja, sem outros elementos e pareceres para que a discussão ocorra de forma plural entre os membros do corpo social. O portal acaba por reproduzir o discurso hegemônico da sociedade e da mídia, que é o de silenciar a narrativa do suicídio, não abrindo margem para que o debate público ocorra em toda a sua plenitude.

\section{Nexo}

O Nexo publica a reportagem O aumento do índice de suicídio de negros no Brasil ${ }^{17}$, escrita por André Cabette Fábio, no dia 7 de junho de 2019. Na linha-fina, o público-leitor já pode ter uma noção das fontes utilizadas pelo portal na abordagem do fato: "O 'Nexo' questionou uma pesquisadora e uma estudante negra de medicina sobre o que pode ser feito para lidar com o problema" ${ }^{17}$. Diferentemente do G1 - Ciência e Saúde, o site informa aos seus leitores que irá trabalhar a temática a partir da visão da população negra, algo que não foi feito pelo primeiro veículo de comunicação analisado neste artigo.

O aumento no índice de suicídio de negros no Brasil
André Cabette Fábio 07 Jun 2019 (atualizado $17 /$ Jun $13 \mathrm{~h} 11$ )
O 'Nexo' questionou uma pesquisadora e uma estudante negra de medicina sobre o que pode ser feito para lidar com o
problema
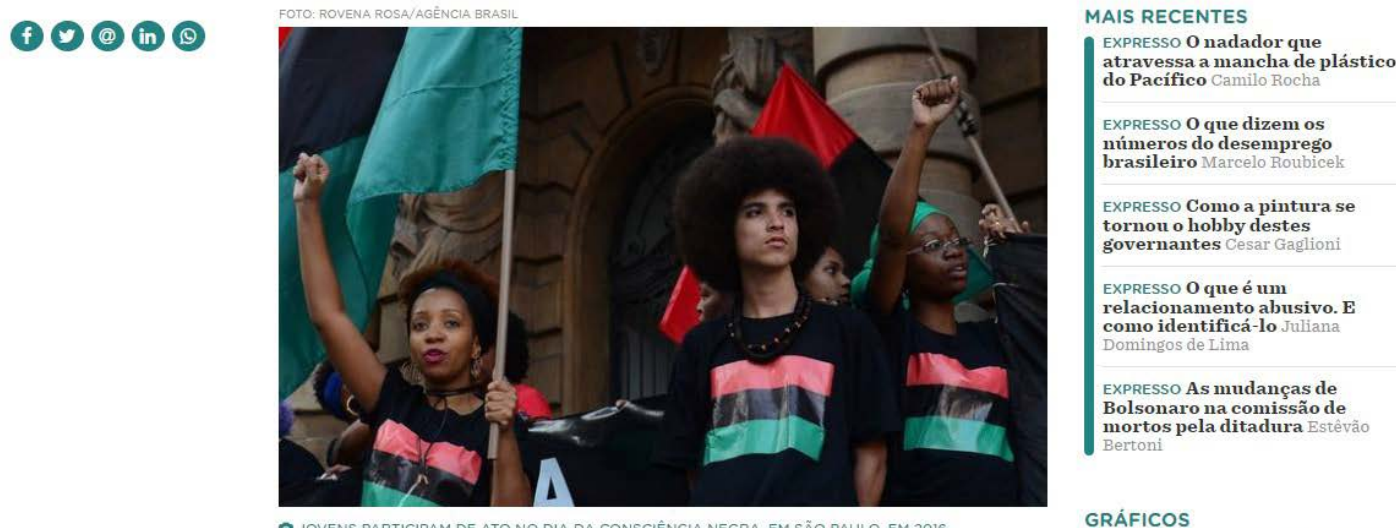

Figura 2 - Reportagem Nexo

Fonte: $\mathrm{NexO}^{17}$. 
O conteúdo oferece um enfoque diferente daquele adotado pelo G1. O texto é iniciado com a informação de que houve a realização do $1^{\circ}$ Seminário Nacional de Saúde da População Negra na Atenção Primária, evento que ocorreu em junho de 2019 na cidade de São Paulo (SP). Na ação, de acordo com o portal de notícias, foram relançados alguns materiais sobre a saúde da população negra elaborados pelo governo federal e pela organização do evento - o Grupo de Trabalho (GT) Saúde da População Negra da Sociedade Brasileira de Medicina de Família e Comunidade (SBMFC). É significativo notar que o Nexo parte de um novo fato sobre a temática de suicídio de negros no Brasil, acrescentando novas informações para o debate público do assunto. Essa tática é conhecida no jornalismo como suíte ${ }^{18}$, que é quando o veículo de comunicação explora os desdobramentos de um fato que já foi notícia em edições anteriores.

Dados do Ministério da Saúde referentes à cartilha Óbitos por Suicídio Entre Adolescentes e Jovens Negros, da SBMFC e do Instituto Brasileiro de Geografia e Estatística (IBGE) sobre a temática são trabalhados já nas primeiras linhas do conteúdo noticioso, oferecendo elementos para que o público-leitor compreenda a problemática de forma mais ampla.

O jornal vai além ao demonstrar como os dados apresentados foram trabalhados e também proporciona uma visão sobre as características da pessoa que se suicida, tais como ambivalência, impulsividade e rigidez. Esse tipo de abordagem vai de encontro aos pensamentos de Schudson ${ }^{10}$ que afirma que as notícias criam para os leitores uma experiência de satisfação estética que os ajudam a interpretar suas próprias vidas e relacioná-las à nação, cidade ou classe a que pertencem.

Uma das organizadoras do Seminário Nacional de Saúde da População Negra na Atenção Primária, Rita Borret, também foi entrevistada pela Nexo, porém, no site ela ganha outras duas identificações: presidente da Associação de Medicina da Família e Comunidade do Rio de Janeiro e coordenadora do Grupo de Trabalho de Saúde da População Negra. Juntamente a ela, é entrevistada a estudante de medicina da Universidade Estadual do Rio de Janeiro (Uerj) e integrante do coletivo nacional de estudantes negros de medicina NegreX, Alanda Gomes. O objetivo da utilização da fala dessas duas especialistas foi compreender os fatores que fazem com que os jovens negros tenham uma predisposição maior a se suicidar e buscar maneiras de como lidar com esse problema.

O repórter do Nexo faz três perguntas para as duas entrevistadas: o que pode ser feito para lidar com o problema do suicídio entre jovens negros; por que há um índice maior de suicídio entre jovens negros; por que há um aumento no número de suicídios dessa população. Entre os tópicos que elas trazem para o debate público estão a necessidade das instituições de saúde de abordar questões relacionadas a raças e etnias nas consultas; o silenciamento da questão de raça nas instituições de saúde pública e na sociedade de modo geral; a necessidade de mais psicólogos e psiquiatras nos Centros de Referência de Assistência Social (CRAS); campanhas de conscientização sobre a importância de se falar sobre a saúde mental; e a situação política e econômica em que o país está inserido nesse momento.

Tanto Borret quanto Gomes abordam a questão da identidade do povo negro. Borret, por exemplo, salienta que os negros descobrem sua identidade durante a juventude, se percebem como indivíduos nesse momento e que a sociedade é racista e entende que o negro necessariamente é inferior, subjugado - este ato, segundo elas, traz um grau de sofrimento maior e leva ao adoecimento e tentativas de suicídio. Ou seja, o racismo estrutural seria o cerne das razões para o aumento do índice de suicídio entre adolescentes e jovens negros.

Diferentemente da primeira reportagem analisada por este artigo, o Nexo traz mais elementos para o debate público e, principalmente, traz a identificação do público-alvo da notícia (negros) com o texto. Há a inserção da fala de uma especialista que pertence a um movimento negro, o que oferece mais legitimidade para tecer comentários sobre o assunto, uma vez que ela faz parte dessa comunidade. Dados, opiniões e aprofundamento da problemática proporcionam mais informações para que o público-leitor possa formar a sua opinião sobre a temática. 
Essa construção da notícia realizada pelo jornal é respaldada pelos pensamentos de Schudson, que diz que o que sustenta a democracia são os grupos e associações que aproximam pessoas, que formulam, articulam e solidificam opiniões e que promovem bases coletivas para ações políticas ${ }^{10}$.

\section{Alma Preta}

A agência de jornalismo especializada na temática racial do Brasil Alma Preta publicou no dia 21 de maio de 2019 a reportagem "Jovens homens negros são 67\% mais vítimas de suicídio do que os brancos”" Escrita pelo repórter Pedro Borges, o conteúdo também aborda, assim como as outras duas notícias analisadas neste artigo, a questão do suicídio de jovens e adolescentes negros a partir dos dados publicados na cartilha Óbitos por Suicídio Entre Adolescentes e Jovens Negros, produzida pelo Ministério da Saúde.

\section{ALMAPREAR.COM}

\begin{tabular}{|c|c|c|c|c|c|}
\hline A HOME & e SOBRE & a EDITORIAS & Q ASSINATURAS & ^ SERVIÇOS & \& CONTATO \\
\hline
\end{tabular}

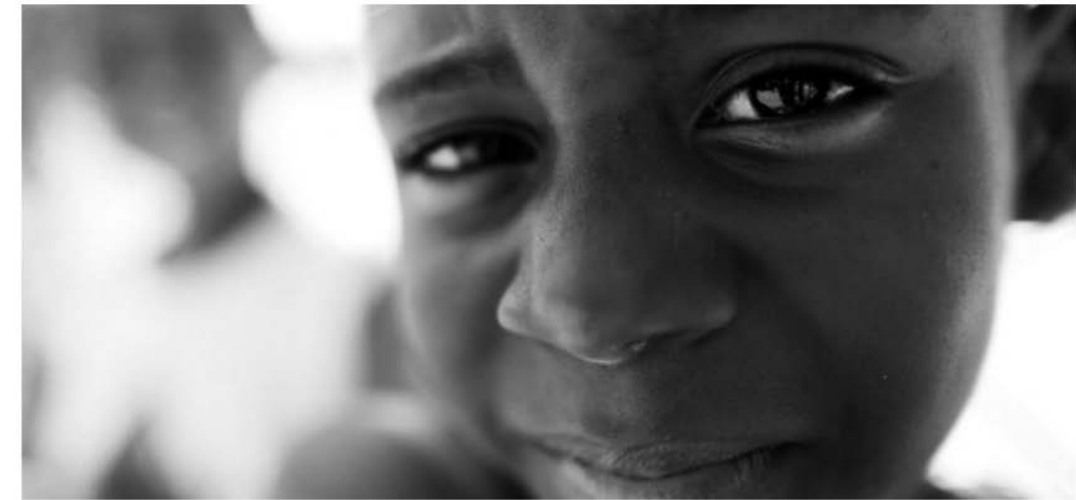

Jovens homens negros são $67 \%$ mais vítimas de suicídio do que os brancos

Pedro Borges pe Realidade

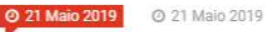

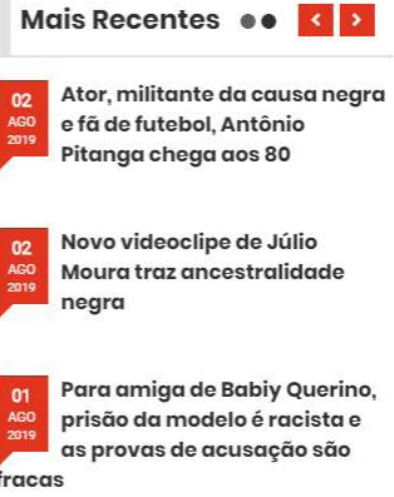

Seja Assinante

Figura 3 - Reportagem Alma Preta Fonte: Alma Preta (2019) ${ }^{19}$

A linha-fina do conteúdo jornalístico explica a origem dos dados "Números fazem parte do estudo 'Óbitos por suicídio entre adolescentes e jovens negros', documento publicado pelo Ministério da Saúde; Racismo é apontado como um dos fatores para essa diferença de mortalidade". A matéria, no entanto, não vai além da cartilha, algo que foi feito tanto pelo Nexo como pelo G1 - Ciência e Saúde. Não há nenhuma entrevista feita pela agência para discussão da temática.

Borges traz informações da cartilha em todos os sete parágrafos do texto, tal como a comparação do suicídio entre jovens do sexo masculino negros e brancos; a variação da taxa desse tipo de morte entre mulheres e homens negros entre os anos de 2012 e 2016; e as causas que podem justificar esses números, tais como o racismo, preconceito e discriminação racial.

O Alma Preta produziu uma reportagem semelhante ${ }^{20}$ (com o uso dos mesmos dados) em janeiro de 2019, porém, novamente a agência especializada preferiu não entrevistar nenhum especialista da área da saúde e/ou membros de organizações que trabalham com questões do público negro.

O site veicula apenas uma visão ampla sobre o assunto, não aprofundando os motivos sobre o aumento dessa ocorrência, bem como possíveis soluções para o problema. O Alma Preta se diz uma agência de 
jornalismo especializada na temática racial do Brasil, por isso, o público-leitor poderia esperar pareceres técnicos, bem como opiniões e considerações de especialistas que atuam nesse segmento e que poderiam oferecer pontos de vistas diferentes sobre o conteúdo, que diz respeito a essa audiência.

A população, especialmente a negra, que busca explicações sobre esse aumento da taxa de suicídio em uma plataforma feita, sobretudo, para esse grupo se vê 'órfã' de opiniões mais aprofundadas e conceitualizadas. É válido salientar que, ao não entrevistar pessoas ligadas ao movimento negro para discorrer sobre esse importante problema de saúde pública, o Alma Preta acaba, consequentemente, fazendo com que seu público não sinta identificação em uma plataforma que se diz voltada para ele.

Diferentemente do G1 - Ciência e Mundo, que trouxe dados e, pelo menos, uma especialista e do Nexo que trouxe, além das informações do Ministério da Saúde, duas fontes, sendo uma delas da comunidade negra, o Alma Preta não se vale dos princípios do jornalismo para produzir um conteúdo diferenciado, como se poderia prezar por uma instituição que se diz voltada para a temática racial do Brasil. A agência acaba adotando o discurso hegemônico dos veículos de comunicação de massa, que apenas informam, mas não contextualizam e/ou trazem novos nuances para que a opinião pública possa discernir e tecer seus próprios pareceres.

Ao não dar voz para a comunidade negra, o Alma Preta acaba por, mesmo que inconscientemente, realizando um silenciamento de sua própria audiência, que poderia desfrutar de conteúdos de mais qualidade, aprofundados e com articulações de diversos membros da sociedade. Não há uma conscientização sobre o problema ou caminhos que as organizações públicas e civis poderiam tomar; existe apenas a informação pela informação, algo que contraria o que Schudson acredita ser o ideal da mídia ao afirmar que os meios de comunicação podem ser vistos não apenas como comunicadores para o público, substitutos para o escrutínio público, mas como guardiões que monitoram o processo político em benefício do público ${ }^{10}$.

No silenciamento provocado pela ausência de membros da comunidade negra, o Alma Preta faz com que os leitores não sintam identificação com o conteúdo, fazendo com que acabem por buscar em outros sites de notícias e plataformas a informação sobre o seu grupo étnico que ansiavam e esperavam da agência.

\section{Discussão}

De todas as reportagens analisadas neste estudo, a notícia publicada pelo Nexo é a que mais oferece elementos para a discussão do tema na sociedade. Com dados e fontes - sendo uma delas da comunidade negra -, o público-leitor tem acesso aos dois lados da questão, recebe opiniões e sugestões de como a questão pode ser tratada e combatida pelas organizações, instituições e associações públicas e civis. Com a inserção de uma especialista que pertence ao grupo negro, o público-leitor também se sente representado ou, pelo menos, tende a se identificar com a fonte.

O G1 - Ciência e Saúde é o site que reforça os estereótipos de veículo de comunicação de massa, embora ainda disponibilize mais elementos que o Alma Preta, tais como dados e uma fonte especialista, que é uma das divulgadoras da cartilha do Ministério da Saúde. Não há, no entanto, nenhum representante da comunidade negra em todo o conteúdo, o que contribui para uma (in)visibilidade social e midiática sobre a questão, além de ressaltar o silenciamento que esses grupos sofrem na mídia, graças a ausência de representatividade e à não oportunidade de serem ouvidas pelo veículo de comunicação.

Orlandi afirma que o silêncio é a capacidade do sujeito trabalhar sua condição constitutiva, sua relação com o 'outro'. Sendo assim, é possível entender que é por meio dele que se constrói a relação do um com o seu múltiplo, ou seja, seria o 'não dito' que é história, à medida que estabelece uma relação de sentido com o imaginário, com a língua e com a ideologia.

O Alma Preta segue o mesmo princípio do G1 - Ciência e Saúde ao não oferecer outros elementos para que o seu público possa se identificar, se sentir acolhido e representado. A utilização de dados oficiais é 
importante para a execução do que se considera um bom jornalismo, mas a agência, que se diz especializada na temática racial do Brasil, poderia trazer mais opiniões e pareceres da comunidade e movimento negros para fomentar a opinião pública sobre o assunto. Quando não há esse esforço por parte do jornalismo, ocorre novamente um silenciamento, fazendo com que o público não sinta identificação com o conteúdo apresentado. O Alma Preta acaba se valendo de elementos da grande mídia, que simplifica a linguagem pois reproduz uma visão simplista de receptor, o qual recebe passivamente a mensagem, tal como era abordado pela Teoria Funcionalista no século XX.

Em nenhum dos três sites, no entanto, encontrou-se a utilização de outros especialistas que não fossem da área da saúde - até mesmo a representante do movimento negro entrevistada pelo Nexo era estudante de medicina e, portanto, também fazia parte do segmento da saúde. O uso de pareceres de sociólogos e/ ou antropólogos poderia enriquecer a discussão sobre a relação entre suicídio e o racismo, apontando para suas raízes na sociedade, suas consequências e as principais formas de combatê-lo.

\section{Considerações finais}

A sociedade constrói a sua opinião pública por meio de suas relações, seja com os indivíduos, as instituições sociais ou a mídia. Os meios de comunicação, portanto, têm como papel presumido fomentar e oferecer elementos para que o debate público possa ocorrer entre os membros da sociedade. Por isso, é tão importante que os conteúdos a serem transmitidos sejam feitos com objetividade e imparcialidade, de modo que o público possa absorver essas informações e, diante das trocas relacionais, tecer seus próprios pareceres sobre diversos assuntos.

Os três veículos de comunicação analisados por esse artigo poderiam trazer importantes elementos para o debate público sobre o suicídio de jovens e adolescentes negros no Brasil, um tema tão válido para a população do nosso país, pois trabalha não apenas com questões de saúde pública, mas também com racismo, preconceito e identidade étnica.

O Nexo, por um lado, oferece mecanismos para que o seu público-leitor possa tecer seus próprios pareceres sobre o assunto. O jornal digital independente garante a participação de duas fontes, sendo uma delas pertencente à comunidade negra, e traz dados, o que fomenta a opinião pública. Ele traz também um senso de identificação para o negro, algo que os outros dois veículos de comunicação analisados não apresentam.

O G1 - Ciência e Saúde reproduz o discurso da mídia hegemônica: ele silencia os apontamentos que poderiam ser apresentados por membros de organizações que atuam na causa negra e faz um debate raso sobre a questão do suicídio de jovens e adolescentes negros. Embora traga dados, a discussão permanece no status quo, não indo além quando o assunto é prevenção e/ou combate desse importante problema de saúde pública.

O Alma Preta poderia ter um papel fundamental no debate público sobre a morte autoprovocada desse grupo social etário, mas ele acaba se valendo do silêncio para reproduzir o discurso da mídia hegemônica. O portal se diz uma agência especializada na temática racial do Brasil e, portanto, o seu público-leitor poderia esperar análises mais aprofundadas, fontes que trouxessem uma identificação com a comunidade e possíveis soluções para o caso. O que se vê, no entanto, é um silenciamento dos negros que não têm voz em um espaço que se diz voltado para suas próprias questões.

Em suma, este artigo levantou pistas que indicam que a mídia ainda comete falhas quando o assunto é a promoção da opinião pública, principalmente quando o objeto é o suicídio, um tema que ainda é tão caro e delicado para a nossa sociedade bem como para a própria comunidade de comunicadores.

Discorrer sobre o suicídio do outro é abordar a problemática da própria morte, algo que ainda constrange o ser humano. Quando os jornalistas silenciam ou oferecem visões assépticas sobre essa problemática, é 
possível que eles estejam desempenhando um mecanismo de defesa contra a dor e o medo de eles próprios provocarem a sua morte.

A análise aqui proposta possui caráter exploratório e não pretende ser conclusiva. Recomenda-se, portanto, outras investigações de produtos jornalísticos, redes sociais digitais e outros dispositivos midiáticos existentes na atualidade para que se possa ampliar o entendimento sobre a questão.

\section{Referências}

1. $\quad$ Ministério da Saúde (BR). Óbitos por Suicídio entre Adolescentes e Jovens Negros 2012 a 2016 [Internet]. Brasília, DF; 2019 [citado em 2019 ago. 1]. Disponível em: http://bvsms.saude.gov.br/bvs/ publicacoes/obitos suicidio adolescentes negros 2012 2016.pdf.

2. Organização Mundial da Saúde. Prevenção do Suicídio: Um Manual para Profissionais da Mídia [Internet]. Genebra; 2000 [citado em 2019 ago. 3]. Disponível em: https://www.who.int/mental health/ prevention/suicide/en/suicideprev media_port.pdf.

3. Moreira B, Paulino F. O. Ética, prática jornalística e cobertura seletiva do suicídio [Internet]. In: $12^{\circ}$ Congreso Latinoamericano de Investigadores de la Comunicación; 2014 ago 6-8 ; Lima, Peru: Alaic; 2014. Disponível em: http://congreso.pucp.edu.pe/alaic2014/wp-content/uploads/2013/11/vGT18Moreira-Oliveira-Paulino.pdf.

4. Schudson M. The sociology of news. New York: WW Norton \& Company; 2002.

5. Lippmann W. Opinião Pública. Petrópolis, RJ: Vozes; 2008.

6. Oliveira I, Barros J. F. A noticiação do suicídio e a ética jornalística: análise do caso Azoica em Imperatriz-MA [Internet]. In: $19^{\circ}$ Congresso de Ciências da Comunicação na Região Nordeste. Fortaleza; 2017 jun 29 - jul 01. São Paulo: Intercom; 2017. Disponível em: http://www.portalintercom. org.br/anais/nordeste2017/resumos/R57-1789-1.pdf.

7. Orlandi EP. As formas do silêncio: no movimento dos sentidos. 4a ed. Campinas: Unicamp; 1997.

8. Associação Brasileira de Psiquiatria (BR). Suicídio: informando para prevenir [Internet]. Brasília, DF: Conselho Federal de Medicina; 2014 [citado em 2019 ago. 3]. Disponível em: http://www.flip3d.com.br/ web/pub/cfm/index9/?numero=14\#page/2.

9. Schudson M. Descobrindo a notícia: uma história social dos jornais nos Estados Unidos. Petrópolis, RJ: Vozes; 2010.

10. Schudson M. The power of news. Cambridge: Harvard University Press; 2003.

11. Thompson JB. Ideologia e cultura moderna: teoria social crítica na era dos meios de comunicação de massa. Petrópolis, RJ: Vozes; 1995.

12. Bastos F, Porto SD. Análise hermenêutica. In: Duarte J, Barros A. Métodos e técnicas de pesquisa em comunicação. São Paulo: Atlas; 2017. p. 316-29.

13. Gomes DCA. Hermenêutica e comunicação: contribuições para compreender a teoria da interpretação e sua aplicação na sociedade midiática. Temática. 2015;9(4):38-52.

14. Pinto MJ. Comunicação e discurso: introdução à análise de discursos. $2^{\mathrm{a}}$ ed. São Paulo: Hacker Editores; 1997.

15. Orlandi EP. Texto e discurso. Organon. 1995;9(23):111-8. doi: https://doi.org/10.22456/2238$\underline{8915.29365}$.

16. Figueiredo P. Índice de suicídio entre jovens e adolescentes negros cresce e é $45 \%$ maior do que entre brancos. G1: Ciência e Saúde [Internet]; 2019 [citado em 2019 ago. 1]. Disponível em: https:// g1.globo.com/ciencia-e-saude/noticia/2019/05/21/indice-de-suicidio-entre-jovens-e-adolescentesnegros-cresce-e-e-45percent-maior-do-que-entre-brancos.ghtml.

17. Fábio AC. O aumento no índice de suicídio de negros no Brasil. Nexo [Internet]; 2019 [citado em 2019 ago. 2]. Disponível em: https://www.nexojornal.com.br/expresso/2019/06/07/O-aumento-no\%C3\%ADndice-de-suic\%C3\%ADdio-de-negros-no-Brasil.

18. Manual de redação da Folha de S.Paulo. Folha Online [Internet]; 1996 [citado em 2019 ago. 2]. Disponível em: https://www1.folha.uol.com.br/folha/circulo/manual_producao s.htm. 
19. Borges P. Jovens homens negros são $67 \%$ mais vítimas de suicídio do que os brancos. Alma Preta [Internet]; 2019 [citado em 2019 ago. 2]. Disponível em: https://www.almapreta.com/editorias/ realidade/jovens-homens-negros-sao-67-mais-vitimas-de-suicidio-do-que-os-brancos.

20. Borges P. Pesquisa aponta que a principal vítima de suicídio no Brasil é o jovem homem negro. Alma Preta [Internet]; 2019 [citado em 2019 ago. 2]. Disponível em: https://almapreta.com/editorias/ realidade/pesquisa-aponta-que-a-principal-vitima-de-suicidio-no-brasil-e-o-jovem-homem-negro. 